УДК 621.396 .96

\title{
АДАПТИВНАЯ ФИЛЬТРАЦИЯ ПАРАМЕТРОВ ДВИЖЕНИЯ ИСТОЧНИКА РАДИОИЗЛУЧЕНИЯ ПРИ КОМПЛЕКСНОМ ИСПОЛЬЗОВАНИИ ДАННЫХ СЕНСОРНОЙ СЕТИ, ПОЛУЧЕННЫХ НА ОСНОВЕ МЕТОДОВ ТDОА И RSS
}

\author{
И. О. ТОВКАЧ, С. Я. ЖУК
}

Национальный технический университет Украиньл

«Киевский политехнический институт им. Игоря Сикорского»,

Украина, Киев, 03056, пр-т Победь 37

\begin{abstract}
Аннотация. На основе математического аппарата смешанных марковских процессов в дискретном времени синтезированы оптимальный и квазиоптимальный адаптивные алгоритмы фильтрации параметров движения источника радиоизлучения с различными видами маневра при комплексном использовании данных сенсорной сети, полученных на основе методов TDOA и RSS. Реализующие их устройства, являются многоканальными и относятся к классу устройств с обратными связями между каналами. Наличие обратных связей между каналами обусловлено марковским свойством дискретного компонента, описывающего виды движения источника радиоизлучения. В квазиоптимальном адаптивном алгоритме обработка измерений, поступающих от датчиков сенсорной сети, выполняется с помощью последовательной процедуры выполнения вычислений. При этом он обеспечивает полигаусовскую аппроксимацию апостериорной плотности вероятности оцениваемого вектора параметров движения источника радиоизлучения. Анализ квазиоптимального алгоритма выполнен с помощью статистического моделирования на ЭВМ на примере оценивания параметров движения БПЛА с различными видами маневра, излучающего радиосигнал.
\end{abstract}

Ключевые слова:БПЛА, метод TDOA, метод RSS, сенсорная сеть,оптимальный и квазиоптимальный адаптивные алгоритмы, параметры движения источника радиоизлучения, комплексное использование данныхсенсорной сети

\section{ВСТУПЛЕНИЕ}

На сегодняшний день все большее внимание привлекают к себе беспроводные сенсорные сети, которые нашли применение в таких областях, как автоматизированный сбор данных, наблюдение и мониторинг окружающей среды. Беспроводная сенсорная сеть представляет собой распределенную, самоорганизующуюся и устойчивую к отказу сеть миниатюрных электронных устройств, обменивающихся информацией по беспроводному каналу связи [1]. В частности, одним из основных применений сенсорных сетей является создание различных систем мониторинга и отслеживание движущихся источников радиоизлучения (ИРИ) как внутри помещения, так и снаружи. Одним из примеров таких ИРИ могут выступать беспилотные летательные аппараты (БПЛА), которые порождают новый класс угроз [2, 3]: падение, вторжение в частную жизнь, фотосъемка засекреченных объектов, контрабанда, возможность терактов, столкновение с воздушными транспортными средствами. Это приводит к необходимости разработки систем, которые решают задачи обнаружения, определения местоположения и параметров движения ИРИ. 
ocalization system: Setup, challenges and results. Proc. of 10th Workshop on Positioning Navigation and Communication, WPNC, 20-21 May 2013, Dresden, Germany. IEEE, 2013. DOI: 10.1109/WPNC.2013.653 3293.

5. Rullan-Lara, Jose L.; Sanahuja, Guillaume; Lozano, Rogelio; Salazar, Sergio; Garcia-Hernandez, Ramon; Ruz-Hernandez, Jose A. Indoor localization of a quadrotor based on WSN: A real-time application. Int. J. Advanced Robotic Syst., Vol. 10, No. 1, 2013. DOI: 10.57 72/53748.

6. Black, Timothy J.; Pathirana, Pubudu N.; Nahavandi, Saeid. Position estimation and tracking of an autonomous mobile sensor using received signal strength. Proc. of Int. Conf. on Intelligent Sensors, Sensor Networks and Information Processing, ISSNIP, 15-18 Dec. 2008, Sydney, Australia. IEEE, 2008, p. 19-24. DOI: 10.1109/ ISSNIP.2008.4761956.

7. Masiero, A.; Fissore, F.; Guarnieri, A.; Pirotti, F.; Vettore A. UAV positioning and collision avoidance based on RSS measurements. Int. Arch. Photogramm. Remote Sens. Spatial Inf. Sci., Vol. XL-1/W4, pp. 219-225, 2015. DOI: 10.5194/isprsarchives-XL-1-W4-219-2015.

8. Tiwari, S.; Darraji, R.; Bassam, S. A.; Kwan, A.; Rawat, K.; Rawat, M.; Fattouche, M.; Ghannouchi, F. M. Practical result of wireless indoor position estimation by using hybrid TDOA/RSS algorithm. Proc. of $23 \mathrm{rd}$ Canadian Conf. on Electrical and Computer Engineering, CCECE, 2-5 May 2010, Calgary, AB, Canada. IEEE, 2010. DOI: $10.1109 /$ CCECE.2010.5575134.

9. Жук, С. Я. Синтез цифровых обнаружителей-измерителей смешанных марковских процессов. Известия вузов. Радиоэлектроника, Т. 32, № 11, С. 31-37, 1989. URI: http://radio.kpi.ua/article/view/S002 134701989110063.

10. Tovkach, Igor O.; Zhuk, Serhii Ya. Adaptive filtration of parameters of the UAV movement on data from its location calculated on the basis the time difference of arrival method. Proc. of 2017 IEEE First Ukraine Conf. on Electrical and Computer Engineering, UKRCON, 29 May-2 June 2017, Kyiv, Ukraine. IEEE, 2017, pp. 160-165. DOI: 10.1109/UKRCON.2017.8100466.

11. Tovkach, I. O.; Zhuk, S. Ya. Recurrent algorithm

1. Баскаков, С. С. Исследование способов повышения эффективности маршрутизации по виртуальным координатам в беспроводных сенсорных сетях. Вестник МГТУ им. Н.Э.Баумана. Серия Приборостроение, № 2, С. 112-124, 2009. URI: http://vestnik prib.ru/catalog/it/hidden/197.html

2. Wallace, R. J.; Loffi, J. M. Examining unmanned aerial system threats \& defenses: A conceptual analysis. Int. J. Aviation, Aeronautics, and Aerospace, Vol. 2, No. 4, 2015. DOI: $10.15394 /$ ijaaa.2015.1084.

3. Защита от дронов - небесный рубеж вашей безопасности. URI: http://dronebouncer.com/.

4. El Gemayel, Noha; Koslowski, Sebastian; Jondral, Friedrich K.; Tschan, Joachim. A low cost TDOA for TDOA localization in sensor networks, J. Aerosp. Technol. Manag., Vol. 9, No. 4, pp. 489-494, 2017. DOI: 10.5028/jatm.v9i4.727.

12. Товкач, И. О.; Жук, С. Я. Адаптивная фильтрация параметров движения БПЛА по данным сенсорной сети на основе измерения мощности принимаемого сигнала. Вестник НТУУ «КПИ». Серия Радиотехника. Радиоаппаратостроение, № 69, С. 41-48, 2017. URI: http://radap.kpi.ua/ru/radiotechnique/article/view/1 $\underline{385}$.

13. Евланов, П. А.; Жук, С. Я. Комплексирование измерителей с отказами. Известия вузов. Радиоэлектроника, Т. 33, № 7, С. 49-53, 1990.

После переработки 17.11.2017 